\title{
Monsoon effect simulation on typhoon rainfall potential - Typhoon Morakot (2009)
}

\author{
Yi-Ling Chang ${ }^{1}$, Hsi-Chyi Yeh ${ }^{2}$, Gin-Rong Liu ${ }^{1,3}$, Chian-Yi Liu ${ }^{1,3}$, Chung-Chih Liu ${ }^{1,4}$, and \\ Tang-Huang Lin ${ }^{1, *}$ \\ ${ }^{1}$ Center for Space and Remote Sensing Research, National Central University, Taoyuan City, Taiwan \\ ${ }^{2}$ Center for General Education, Aletheia University, New Taipei City, Taiwan \\ ${ }_{3}^{3}$ Department of Atmospheric Sciences, National Central University, Taoyuan City, Taiwan \\ ${ }^{4}$ The Teaching Centre of Natural Science, Minghsin University of Science and Technology, Hsinchu, Taiwan
}

\begin{abstract}
Article history:
Received 27 November 2015

Revised 9 May 2016

Accepted 17 August 2016

Keywords:

Typhoon rainfall potential, Southwesterly monsoon, Low-level wind speed, Convergence, Water vapor content, WRF model, 3D-Var system

\section{Citation:}

Chang, Y. L., H. C. Yeh, G. R. Liu, C. Y. Liu, C. C. Liu, and T. H. Lin, 2017: Monsoon effect simulation on typhoon rainfall potential - Typhoon Morakot (2009). Terr. Atmos.

Ocean. Sci., 28, 11-21, doi: 10.3319/ TAO.2016.08.17.01(CCA)
\end{abstract}

\begin{abstract}
A record breaking extreme precipitation event produced $3000 \mathrm{~mm}_{\text {day }}{ }^{-1}$ of accumulated rainfall over southern Taiwan in August 2009. The interactions between Typhoon Morakot and the prevailing southwesterly (SW) monsoon are the primary mechanism for this heavy precipitation during 5 - 13 August 2009. This extreme precipitation could be produced by the abundant moisture from the SW monsoon associated with the interaction between typhoon and monsoon wind fields, leading to severe property damage. The accurate mapping of extreme precipitation caused from the interaction between a monsoon and typhoon is critical for early warning in Taiwan. This study simulates the heavy rainfall event is based on the Weather Research and Forecast system model (WRF) using the three nested domain configuration. Using data assimilation with a virtual meteorological field using the 3D-Var system, such as wind field to alter the SW monsoon strength in the initial condition, the impacts of intensified convergence and water vapor content on the accumulated rainfall are analyzed to quantize the intensification of typhoon rainfall potential. The results showed a positive correlation between the enhanced precipitation and the intensity of low-level wind speed convergence as well as water vapor content. For the Typhoon Morakot case study the rainfall for could attain approximately $2 \times 10^{4} \mathrm{~mm}$ at 6 hours interval in the southern Taiwan area when $10 \times 10^{-6} \mathrm{~s}^{-1}$ convergence intensified at $850 \mathrm{hPa}$ level around the southern part of the Taiwan Strait. These results suggest that low-level wind speed, convergence and water vapor content play key roles in the typhoon rainfall potential coupled with the SW monsoon.
\end{abstract}

\section{INTRODUCTION}

Predicting the accumulated rainfall before typhoon landfall is a challenging weather forecast and prediction task for authorities. Accurate weather prediction is crucial for disaster mitigation. In August 2009, Typhoon Morakot produced record-breaking accumulated rainfall over southern Taiwan. The extreme rainfall brought in by Typhoon Morakot is associated with Taiwan's topography effect, while the interactions involved several multi-scale weather features, such as the monsoon gyre, moist winds and a nearby typhoon (Wu 2013). During the Typhoon Morakot (2009)

\footnotetext{
* Corresponding author

E-mail:thlin@csrsr.ncu.edu.tw
}

period, the rainfall intensity was enhanced by the convergence of typhoon circulation and the monsoon wind field [southwest and northeast (NE)] with abundant water vapor content, causing extreme flooding and landslide events. Figure 1a shows that A-Li Shan station $\left(23.5^{\circ} \mathrm{N}\right.$ and $120.8^{\circ} \mathrm{E}, 2413 \mathrm{~m}$ in elevation) recorded $1533.5 \mathrm{~mm}$ of rain in 24 hours on 8 August 2009. This rainfall brought catastrophic damage to Taiwan, e.g., more than 600 people died with NT\$ 100 billion in economic losses. For these reasons having accurate, timely typhoon rainfall intensity information is a vital issue for disaster mitigation in Taiwan during typhoon season.

Satellite observation data has been most useful in the 
recent decades for typhoon rainfall monitoring and forecasting. The Tropical cyclone Rainfall Potential (TRaP) (Kidder et al.2005) is a technique to obtain the typhoon rainfall from its shift-motion and the cyclone track prediction. The TRaP is also the first time satellite data were adopted for typhoon rainfall potential (TRP). However, this method did not consider the typhoon rain band rotation and orographic effect. Therefore, TRaP usually is unsatisfactory in corresponding well with the actual rainfall, especially for the complex terrain areas in Taiwan. Liu et al. (2012) addressed these issues and enhanced it as the improved Tropical cyclone Rainfall Potential (I-TRaP) technique. The I-TRaP approach considers the Tropical Cyclone (TC) spiral rain band rotation and also takes topographic and monsoon effects into account for remapping and rescaling the TC rainfall spatial pattern and intensity. The TC rainfall spatial distribution (remapping) is constructed as a function of the TC location according to historical ground truth and satellite retrievals (about 73 cases from 1997 to 2008). Through these efforts, I-TRaP could include the topographic effect and the TC spiral rain band rotation. It has been proven that the I-TRaP approach can be mapped using rain gauge data very well with the correlation up to 0.66 on average.

For instance, the I-TRaP rainfall distributions shown in (Figs. 1b and e) illustrate satisfactory consistency with the ground measurements (Figs. 1a and d) for both Typhoons Haitang (2005) and Morakot (2009). These two cases present similar tracks but different southwesterly (SW) monsoon strength. Figures $1 \mathrm{c}$ and $\mathrm{f}$ show the impacts on TC rainfall intensity due to this reason. The maximum intensity of Typhoon Morakot (Fig. 1b) around the southern mountainous region is underestimated by approximately $500 \mathrm{~mm} \mathrm{day}^{-1}$ than the rain gauge measurement (Fig. 1a). For the case of Typhoon Haitang (2005) with weaker SW monsoon (Figs. 1d, e, and f), the rainfall potential was overestimated. These discrepancies might be because the coupling effects between the typhoon circulation and seasonal monsoon on the rainfall intensity wind field and water vapor flux convergence/divergence was not considered.

The limitation in analyzing and quantifying monsoon effects for TRP improvement in terms of satellite observation and reanalysis dataset does not provide stepwise monsoon intensity for a case study. Numerical simulation seems the primary solution to overcome these related issues. Using virtual wind field assimilation, the quantitative monsoon effect analysis with different strengths is proposed in this study. The Weather Research and Forecast (WRF) model is employed to simulate the seasonal monsoon coupling (a) Gouge-Rainfall (2009Morakot)

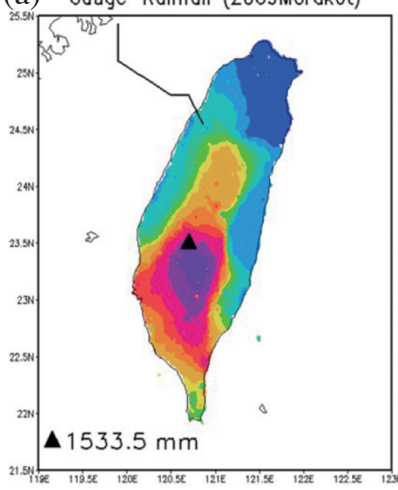

(d) Gauge-Rainfall (2005Haitang)

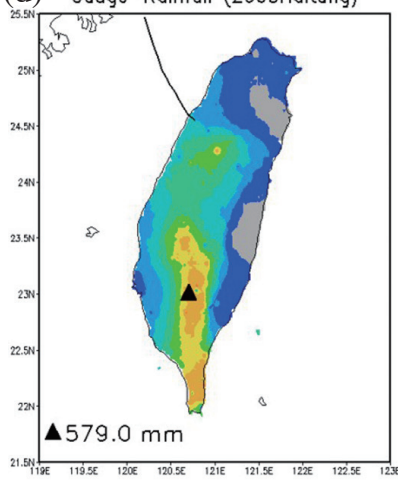

(b) Improved TRaP Rainfall (2009Morakot)

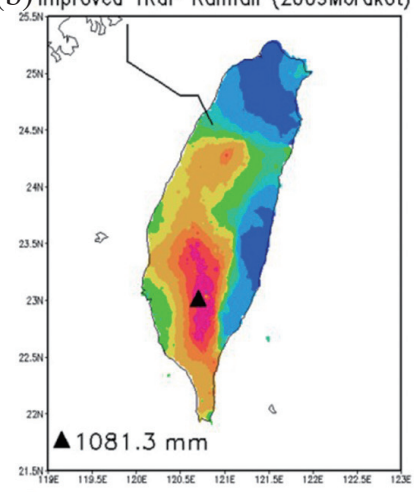

(e) Improved TRaP Rainfall (2005Haitang)

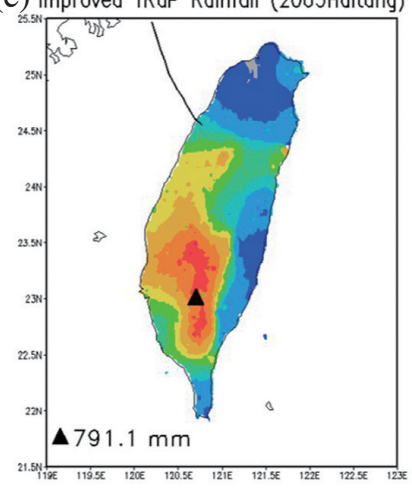

(c)

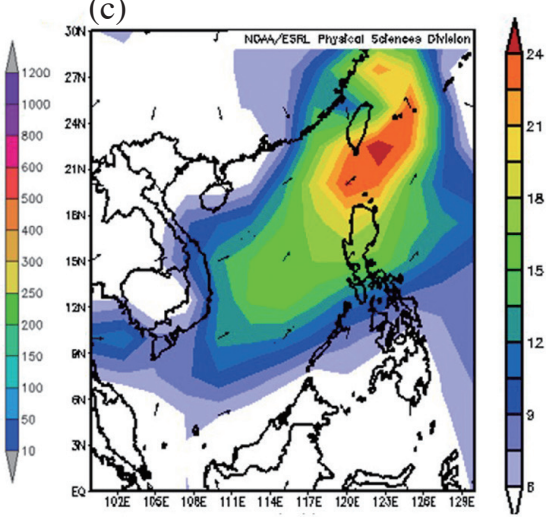

(f)

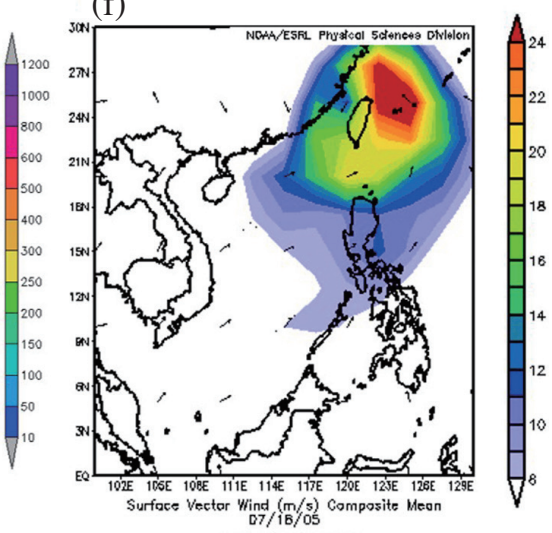

NCEP/NCAR Reonolysis

Fig. 1. The 24-hr accumulated rainfall (mm) from (a) ground station and (b) I-TRaP of Morakot (2009), and (c) the daily averaged surface wind speed on 8 August 2009 during the period of Typhoon Morakot. (d), (e), and (f) are the same as (a), (b) and (c), but for Typhoon Haitang on 18 July 2005. The black line indicates the typhoon track from the Central Weather Bureau (CWB). 
effect on typhoon rainfall intensity with water vapor flux and monsoon strength. The objective is to analyze and quantify the correlations between environmental variables, such as monsoon strength, convergence and water vapor content and typhoon rainfall intensity. The results will lead to further I-TRaP improvement in typhoon rainfall forecasting.

\section{DATA AND METHODOLOGY}

\subsection{Data}

The interactions between environmental variables and rainfall intensity during typhoon coupling with a monsoon were conducted using global reanalysis from the European Center for Medium range Weather Forecasting (ECMWF) forecast model. The ECMWF/ERA-Interim (Dee et al. 2011) spatial resolution is approximately 0.7 degrees with 37 atmospheric levels in a 6-hr temporal resolution. The environmental variables during the typhoon periods are derived from the ECMWF dataset, including the convergence strength, water vapor content and monsoon wind field. For TRP examination the TC rainfall distribution input data, tropical storm spiral rain band rotational speed, best typhoon track and Rain Rate (RR) from observations are required for I-TRaP input. Rainfall data were collected from the Central Weather Bureau (CWB) rain gauge network Data Bank for Atmosphere Research (DBAR) as listed in Table 1. The data from the Special Sensor Microwave Imager (SSM/I) and the Special Sensor Microwave Imager Sounder (SSMIS) were used to estimate TC rainfall distribution. SSM/I and SSMIS onboard the Defense Meteorological Satellite Program (DMSP) satellites are passive microwave radiometers. The geostationary satellite data provide hourly infrared images to estimate the tropical storm spiral rain band rotational speed. It includes the Geostationary Meteorological Satellite 5 (GMS-5), Geostationary Operational Environmental Satellites 9 (GOES-9), and Multi-functional Transport Satellites-1R (MTSAT-1R). The best track data from the US Navy's Joint Typhoon Warning Center (JTWC) were used in I-TRaP for positioning the typhoon's center. RR is sourced from Taiwan's automatic rainfall observation station data from DBAR.

\subsection{WRF Model}

The Advanced Research WRF (ARW) model is utilized to configure analysis sensitivity through numerical experiments using the scheme shown in Fig. 2. The WRF simulation with three nested domains is initialized using the NCEP/FNL (National Centers for Environmental Prediction/National Weather Service/NOAA/U.S. Department of Commerce 2000) reanalysis at one degree resolution. Three horizontal resolution domains 45,15 , and $5 \mathrm{~km}$ are used in Fig. 3. Twenty-seven vertical levels at sigma coordinates are considered for the simulations performed from 18:00 UTC
7 Aug to 00:00 UTC 9 Aug 2009. The boundary conditions for the ARW simulation are interpolated for the NCEP/FNL data set. Table 2 shows the physical and dynamic options configuration in the WRF model. The ARW details are presented in the study of Skamarock et al. (2008).

\subsection{Sensitivity Experiments}

TRP sensitivity to SW monsoon intensity with the virtual wind fields in South China Sea (SCS) will be examined as the colored boxes indicate in Fig. 4. The SW monsoon virtual intensity is simulated by scaling the NCEP/FNL wind field data within the boxed area as shown below,

$u_{v}=$ factor $\times u_{F N L}$

$v_{v}=$ factor $\times v_{F N L}$

Where, $u_{v}$ and $v_{v}$ are the $\mathrm{u}$ - and v-components in the virtual wind field, respectively, while $u_{F N L}$ and $v_{F N L}$ represent the uand v-wind speed components from the NCEP/FNL dataset. The virtual wind field is generally requested to be consistent

Table 1. The typhoon coupling with SW monsoon around Taiwan Island.

\begin{tabular}{cc}
\hline Typhoon & Monsoon type \\
\hline 2004 Mindulle & SW \\
2005 Haitang & SW \\
2008 Fung-wong & SW \\
2009 Morakot & SW \\
\hline
\end{tabular}

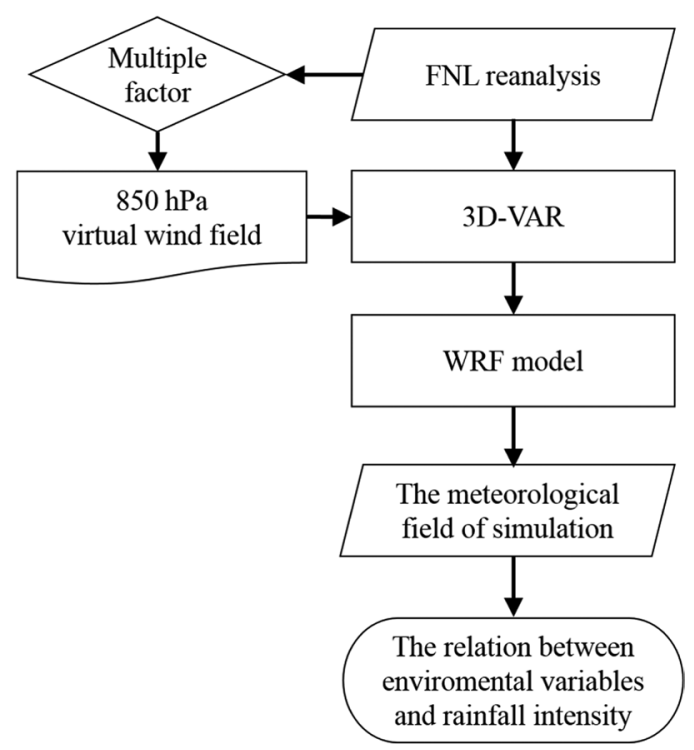

Fig. 2. The flowchart of this study. 


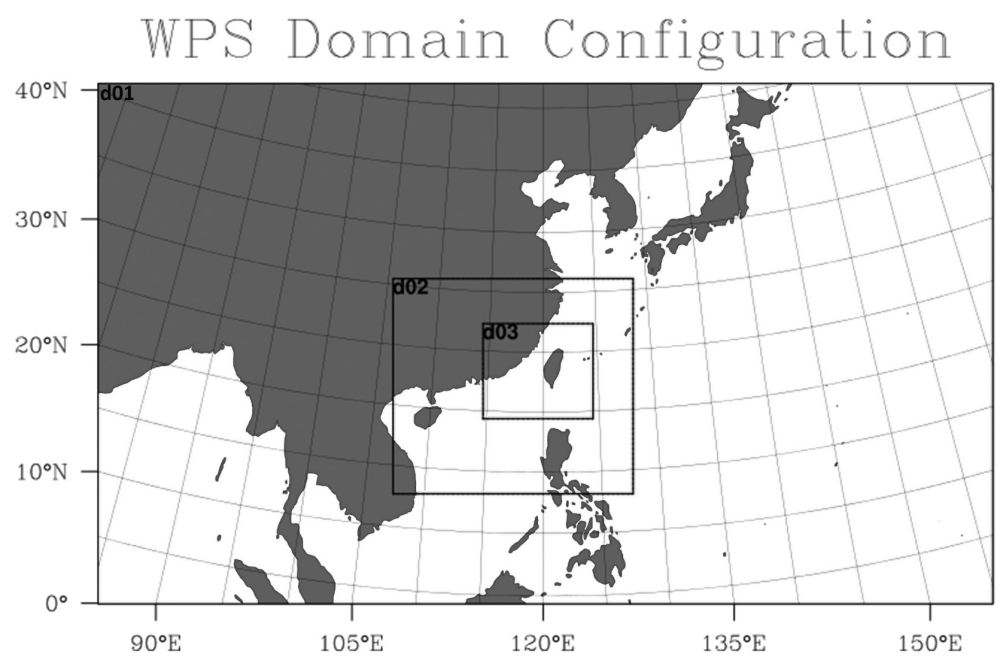

Fig. 3. The three nested domains in this study.

Table 2. Physics and Dynamics options setup in the WRF model.

\begin{tabular}{cc}
\hline Parameter & Scheme \\
\hline Microphysical parameterization & WSM5 (Hong et al. 2004; MWR) \\
Cumulus Parameterization & Kain-Fritsch (Kain 2004; JAM) \\
Shortwave radiation & Dudhia (Dudhia 1989; JAS) \\
Longwave radiation & RRTM (Mlawer et al. 1997; JGR) \\
Planetary boundary layer (PBL) & YSU (Hong et al. 2006; MWR) \\
\hline
\end{tabular}

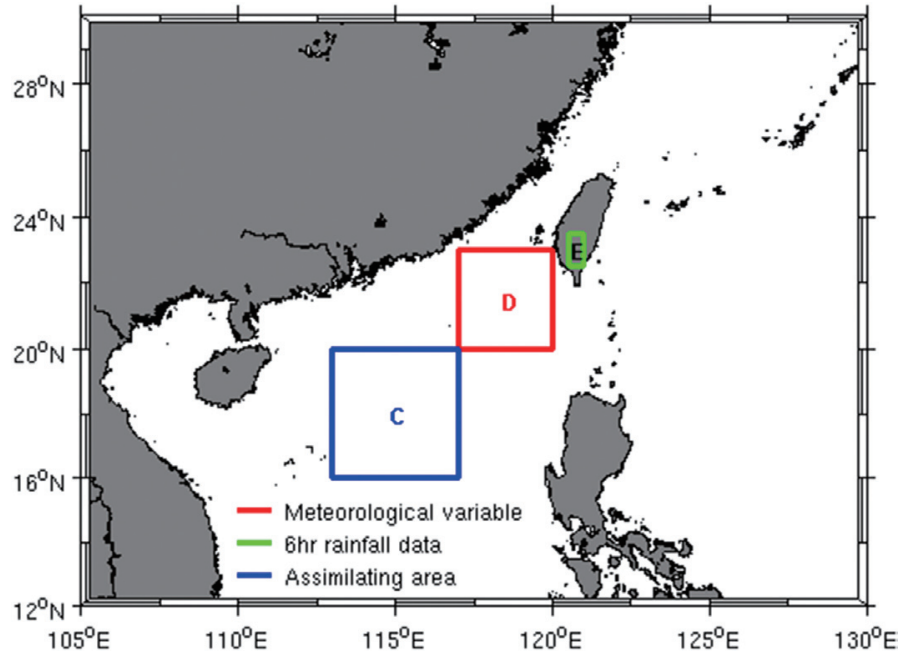

Fig. 4. Area C (blue box) indicates the data assimilation area. Area D (red box) is selected for its meteorological variables. The 6-hr accumulated rainfall is computed from Area E (green box). 
with the meteorological parameters in the background domain before model computing, that is the data assimilation. The three-dimensional variation data assimilation (3D-Var) system was introduced in the Canadian Meteorological Centre (CMC) operational suite in 1997 in preparation for the direct satellite radiance assimilation (Gauthier et al. 1999; Chouinard et al. 2001). The 3D-Var virtual wind field simulation was used to modify the SW monsoon on the SCS to determine the rainfall increment/reduction contributed by different southwest monsoon intensities.

In addition to SW monsoon intensity, the rainfall pattern is principally distributed by the typhoon location and wind radius. Cheung et al. (2008) revealed the TC rainfall pattern characteristics in Taiwan, suggesting that the rainfall distribution can be highly related to the TC center location as Fig. 5 illustrates. Therefore, the typhoon track is fairly significant to the rainfall pattern and intensity in Taiwan. According to the study of Wu et al. (2009), the simulated typhoon track is sensitive to the monsoon strength in the deep layer (1000 - $300 \mathrm{hPa})$. Chen et al. (2005) pointed out that weather systems such as low-level jets at 850 and $700 \mathrm{hPa}$ are usually associated with heavy rainfall events. Hence, the lower level wind field (i.e., $850 \mathrm{hPa}$ ) is selected for data assimilation in this study. The virtual monsoon strengths are controlled by factors of $0.01,0.25,0.50,0.75,1.00,1.5$, and 2.0 for model simulation within 18 hours after data assimilation. The first 6 hours simulation is removed for model spin up. Therefore, the SW intensity impacts over the SCS on TRP can be examined and quantified based on these simulations.

\section{RESULTS AND DISCUSSIONS}

\subsection{Convergence and Specific Humidity Effects on Rainfall Intensity}

Because the convergence and water vapor flux are the essential variables to rainfall intensity, their effects received first investigation priority. From the assessments between the I-TRaP results and ground truths, Area A (Fig. 6a) is selected for the SW monsoon variables over the SCS (Liu et al. 2012). When comparing the discrepancy between the gauge rainfall and I-TRaP rainfall potential along with the

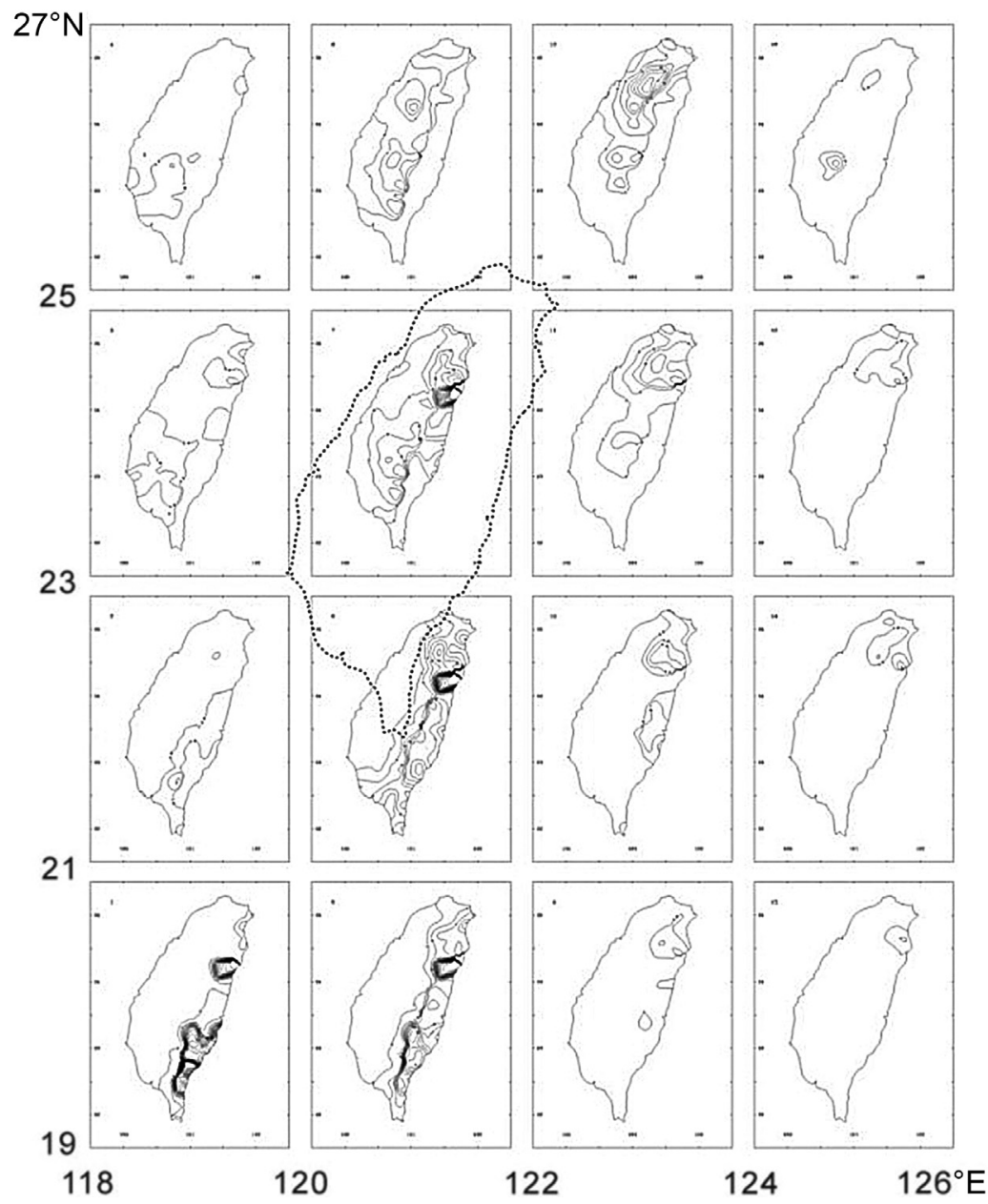

Fig. 5. TC rainfall climatology in the Taiwan area (contour lines are hourly RR with $2 \mathrm{~mm} \mathrm{~h}^{-1}$ interval). Each $2^{\circ} \times 2^{\circ}$ panel represents the RR distribution when the TCs are centered in that panel (Cheung et al. 2008). 

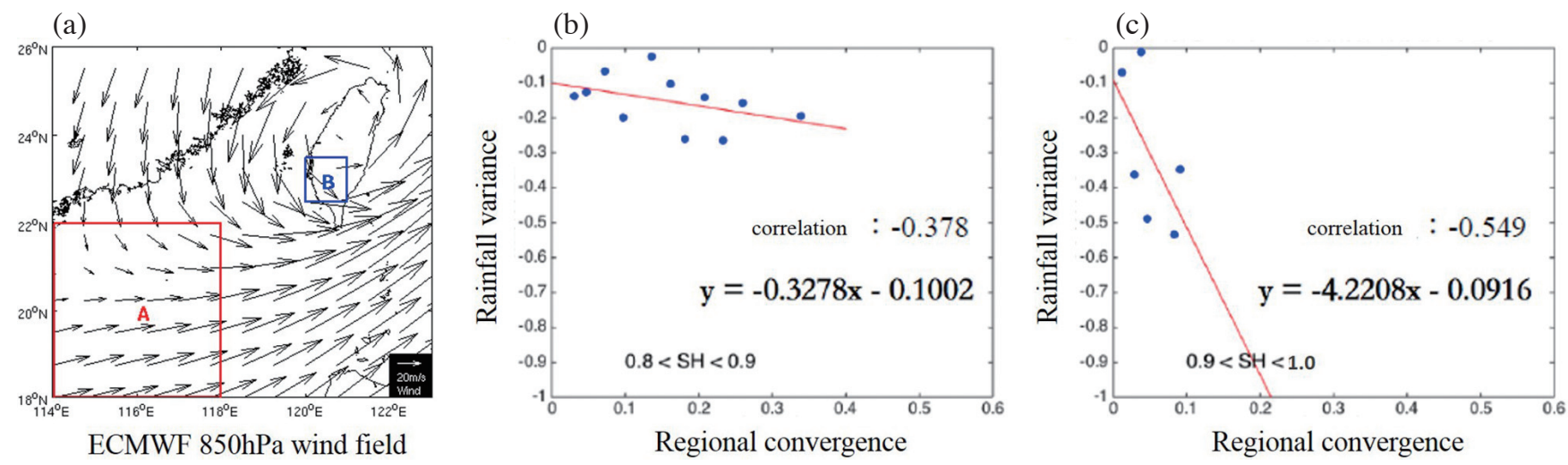

Fig. 6. (a) $850 \mathrm{hPa}$ wind field at $00 \mathrm{Z} 08$ August 2009. Area A is $4^{\circ} \times 4^{\circ}$ and contains 256 grid points, Area $\mathrm{B}$ is $1^{\circ} \times 1^{\circ}$. The correlation between rainfall variation and normalized convergence with specific humidity $(\mathrm{SH})$ in the range of (b) $0.8-0.9$ and (c) $0.9-1.0$.

convergence and specific humidity from the NCEP/FNL dataset, the variation in rainfall intensity is the function of convergence and water vapor flux variables. Figure 6 illustrates the results from 4 typhoons coupled with the SW monsoon in Table 1. The I-TRaP rainfall pattern is quite consistent with the gauge measurements (Figs. 1a and b) while the intensity is still different. In reviewing, the sensitive areas where obvious discrepancies in rainfall intensity occur, Area B in southern Taiwan (Fig. 6a) is selected as the responsive rainfall variation region for further analysis. All of the environmental variables (mean value of Area A) and rainfall intensity (mean values for Area B) were normalized to perform a fair comparison between the different typhoon and monsoon strength cases. Figures $6 \mathrm{~b}$ and $\mathrm{c}$ indicate the correlations between the I-TRaP rainfall variation and divergence under different specific humidity levels. The greater the SCS convergence increases, the greater the variation (underestimation) in rainfall intensity. Furthermore, the rainfall variation could be much enhanced under circumstances with higher specific humidity, as suggested by the results demonstrated in Fig. 6. The convergence and water vapor flux are significant to typhoon rainfall intensity in Taiwan. However, the evidence shows that environmental variables are also interacting with each other, thus the model simulation is employed for further sensitivity analysis in this study.

\subsection{The Regions for Sensitivity Experiment}

As we know, typhoon track and intensity simulations may be altered after data assimilation with the virtual wind field. In order to eliminate the changes from the induced virtual wind field, the 850hpa virtual wind fields from 7 regions (Fig. 7a) were tested. The sensitivity is evaluated using comparisons with the references including the average typhoon wind speed within $1 \mathrm{~km}$ radius from the typhoon center, the erroneous of typhoon track from the JTWC, and the SW monsoon wind field within Area D in Fig. 4. The results suggest that exp3 has the smallest difference in typhoon intensity and track and apparent response to the SW monsoon, as shown in Fig. 7b. Therefore, the region 113 - $117^{\circ} \mathrm{E}$ and $16-20^{\circ} \mathrm{N}$ (known as "Area C" in Fig. 4), is chosen for the data assimilation area in this study.

For the model simulation, the district sensitivity to rainfall intensity is investigated to determine the representative region for analysis related to typhoon rainfall intensity. The areas over the SCS with consequential effects on rainfall intensity in Taiwan were examined, as the test areas listed in Table 3. According to the best relationship between rainfall intensity and regional wind field, the second area $\left(117-120^{\circ} \mathrm{E}, 20-23^{\circ} \mathrm{N}\right)$ has the highest correlation with rainfall intensity, and thus is selected as the region for further typhoon rainfall intensity with SW monsoon coupled analysis (known as "Area D" in Fig. 4).

\subsection{Data Assimilation of Virtual Wind Field}

The virtual wind fields with factors of $0.01,0.25,0.5$, $0.75,1.5$, and 2.0 at $850 \mathrm{hPa}$ level are assimilated using the 3D-Var system for SW monsoon strength adjustment. Figure 8 shows the variance in wind speed over the domain area. The wind speed around the factored area after assimilating is accordant with the factor value demonstrating that the proposed method for virtual wind field can reasonably modulate the monsoon strength. Figure 8 also exhibits the typhoon wind speed increases when the SW monsoon strengthens and vice versa. More water vapor content is supplied from the SW monsoon to intensify the terrain effect on precipitation. The 6-hr accumulated rainfall in southern Taiwan also agrees with the assimilated wind fields as shown in Fig. 9. It suggests that a stronger monsoon will produce more precipitation in southern Taiwan. Table 4 shows the SW monsoon strength will further affect the wind speed and moisture flux in the red box area. The blue box area (Area C in Fig. 4) is selected to assimilate the virtual wind field for the model simulation. 
(a)

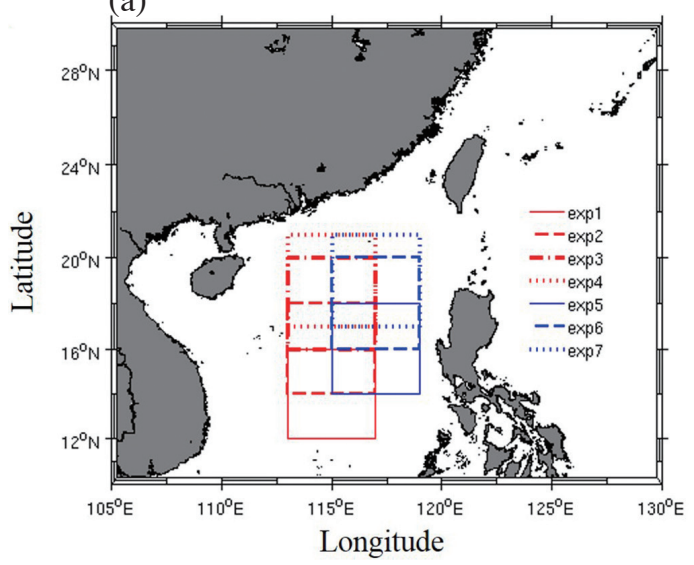

(b)

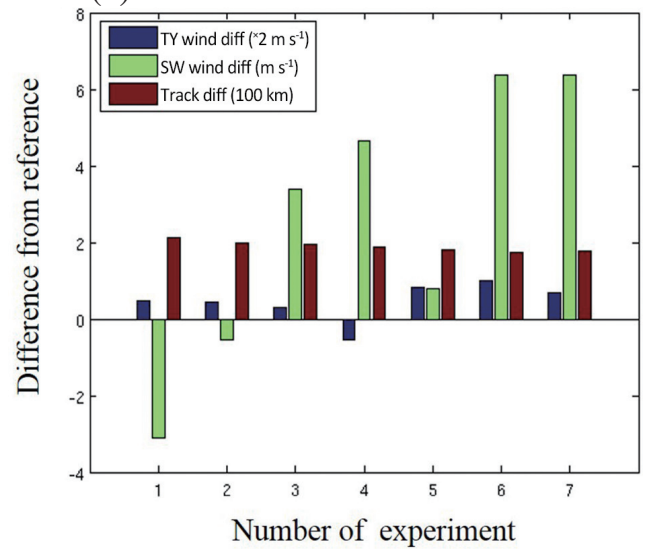

Fig. 7. (a) The regions for sensitivity tests to evaluate the region through data assimilating can efficiently modify the SW monsoon strength with not too much impact on the typhoon intensity and track. (b) The differences in typhoon wind speed (blue bar), SW monsoon wind speed (green bar), and erroneous typhoon track (brown bar) between the experiment and control run.

Table 3. The linear regression statistical results between the wind field and rainfall intensity in different areas.

\begin{tabular}{cccc}
\hline No. & Test area & R-square & Correlation \\
\hline 1 & $20-23^{\circ} \mathrm{N}, 114-117^{\circ} \mathrm{E}$ & 0.72 & 0.85 \\
2 & $20-23^{\circ} \mathrm{N}, 117-120^{\circ} \mathrm{E}$ & 0.82 & 0.90 \\
3 & $23-26^{\circ} \mathrm{N}, 114-117^{\circ} \mathrm{E}$ & 0.71 & 0.84 \\
4 & $23-26^{\circ} \mathrm{N}, 114-117^{\circ} \mathrm{E}$ & 0.61 & 0.78 \\
\hline
\end{tabular}
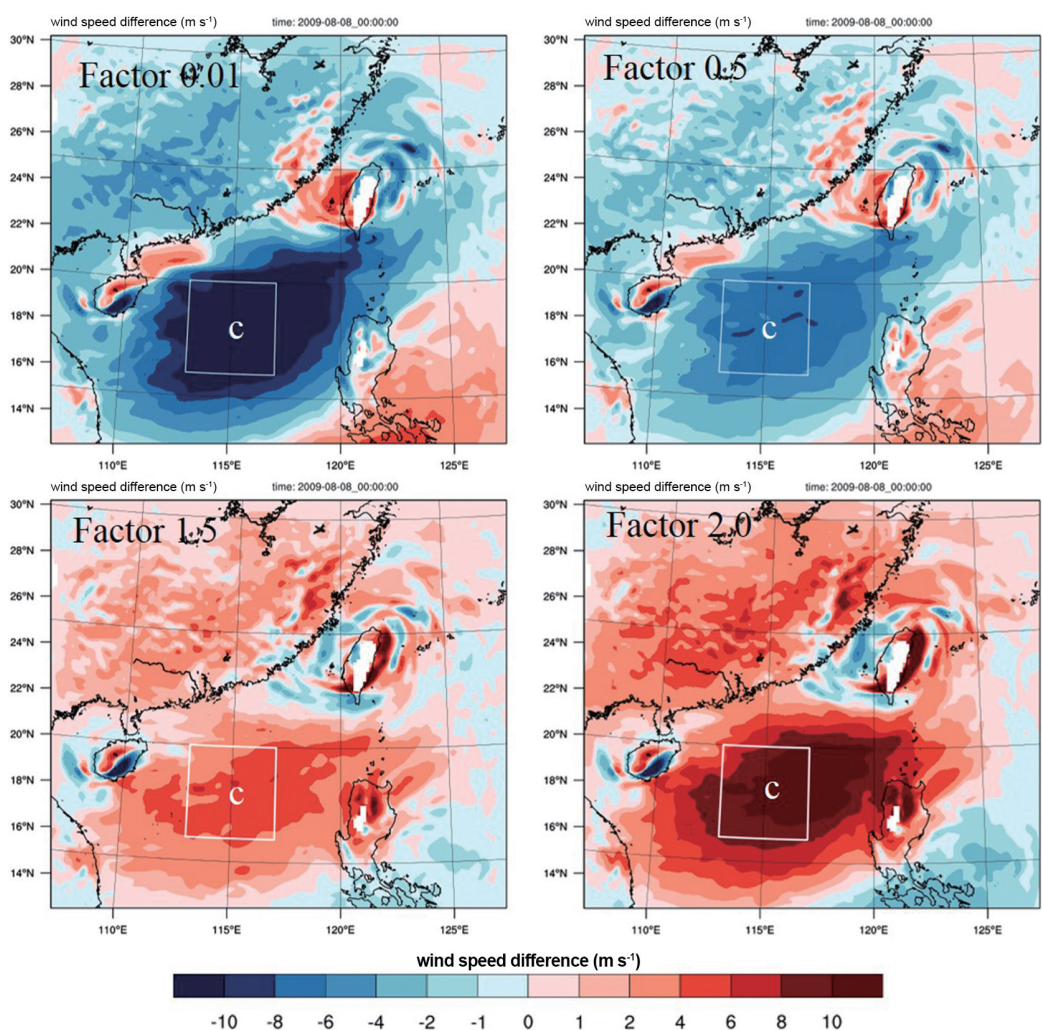

Fig. 8. The difference in $850 \mathrm{hPa}$ wind speed between virtual wind fields (with the factor value of $0.01,0.5,1.5$, and 2.0 ) and control run after assimilation at $18 \mathrm{Z} 07$ August 2009 (exp-ctrl). The white square indicates the virtual wind field inserted area. 

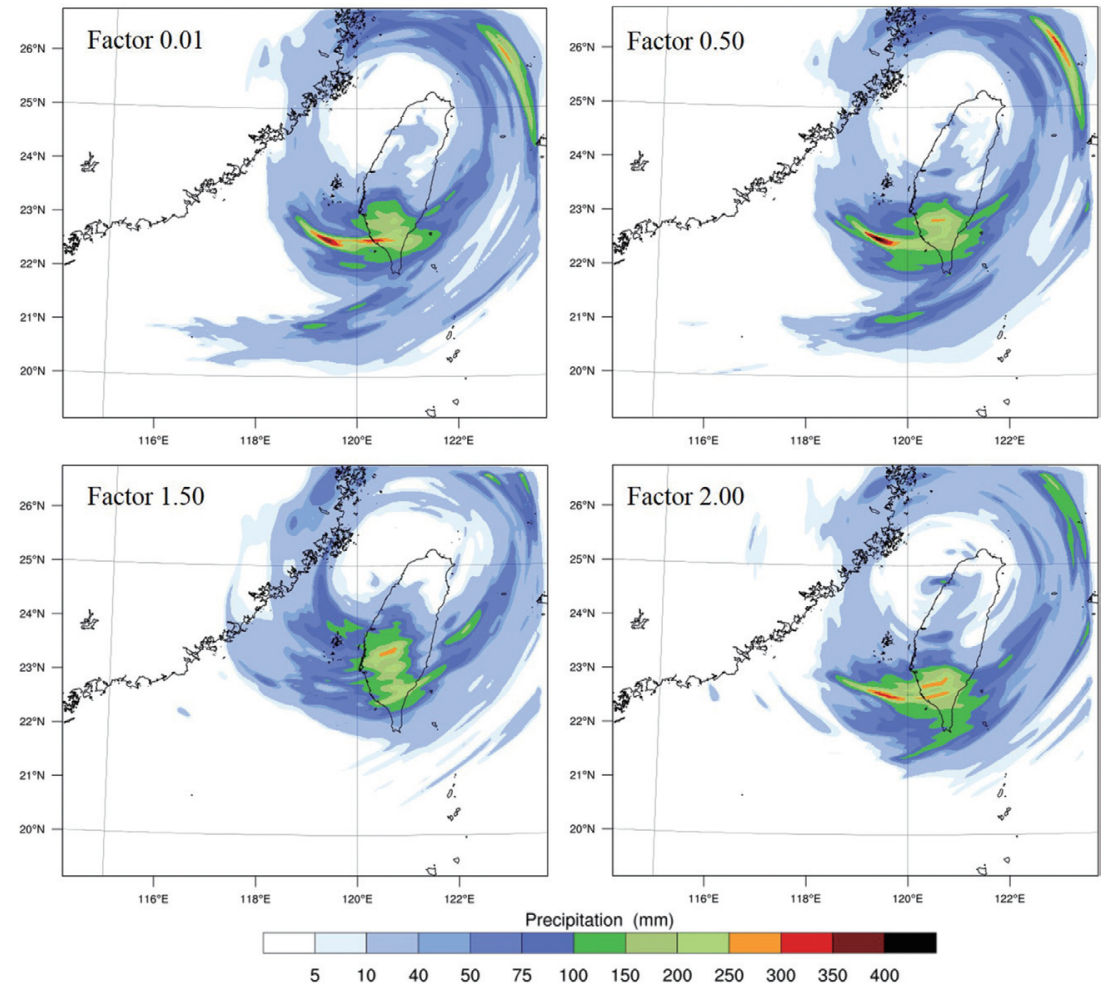

Fig. 9. The 6-hr accumulated rainfall intensity from different factor (i.e., 0.01, 0.5, 1.5, and 2.0) which control the monsoon strength over SCS

Table 4. The wind speed and moisture flux in Area D after data assimilation with virtual wind fields. The virtual wind field speed is controlled using these factors.

\begin{tabular}{ccc}
\hline Factor & Wind speed $\left(\mathrm{m} \mathrm{s}^{-1}\right)$ & Moisture flux $(\mathrm{g} \cdot \boldsymbol{m} / \mathbf{k g} \cdot \boldsymbol{s})$ \\
\hline 0.01 & 23.06 & 0.37 \\
0.25 & 22.71 & 0.37 \\
0.50 & 22.85 & 0.38 \\
0.75 & 22.98 & 0.39 \\
1.00 & 23.03 & 0.39 \\
1.50 & 23.22 & 0.40 \\
2.00 & 23.86 & 0.41
\end{tabular}

\subsection{Simulation of SW Monsoon Effect}

The control run results from the ARW model for Typhoon Morakot is demonstrated in Fig. 10 with the wind field and divergence at $850 \mathrm{hPa}$ (left panels) and the corresponding 6-hr accumulated rainfall and moisture flux (right panels) from 12:00 to 24:00 UTC on 8 August 2009. It presents the convergence and accumulated rainfall are well collocated in Fig. 10, indicating the significance of convergence in rainfall potential. That is, the convergence generated by the typhoon and SW monsoon interaction would contribute extra precipitation if the water vapor supply is continued. In the case study, the convergent zone over south Taiwan
Strait (left column) is obvious exhibiting the coupling effect from the typhoon and SW monsoon, which may enrich the rainfall intensity with the supporting water vapor.

Three regions of interest (ROI) were selected according to the sensitivity tests to quantitatively evaluate the SW monsoon effect on typhoon rainfall intensity. An averaged meteorological variable from Area D $\left(117-120^{\circ} \mathrm{E}, 20-23^{\circ} \mathrm{N}\right)$ and the total 6-hr rainfall (sum of the simulated rainfall grid point data) from Area $\mathrm{E}\left(120.5-121^{\circ} \mathrm{E}, 22.5-23.5^{\circ} \mathrm{N}\right)($ Fig. 4) were produced from the ARW model simulations after virtual wind field assimilation (Area C), as depicted in Fig. 4. The results display that the 6-hr accumulated rainfall is sensitive to wind speed at $850 \mathrm{hPa}$, and good linear relation 

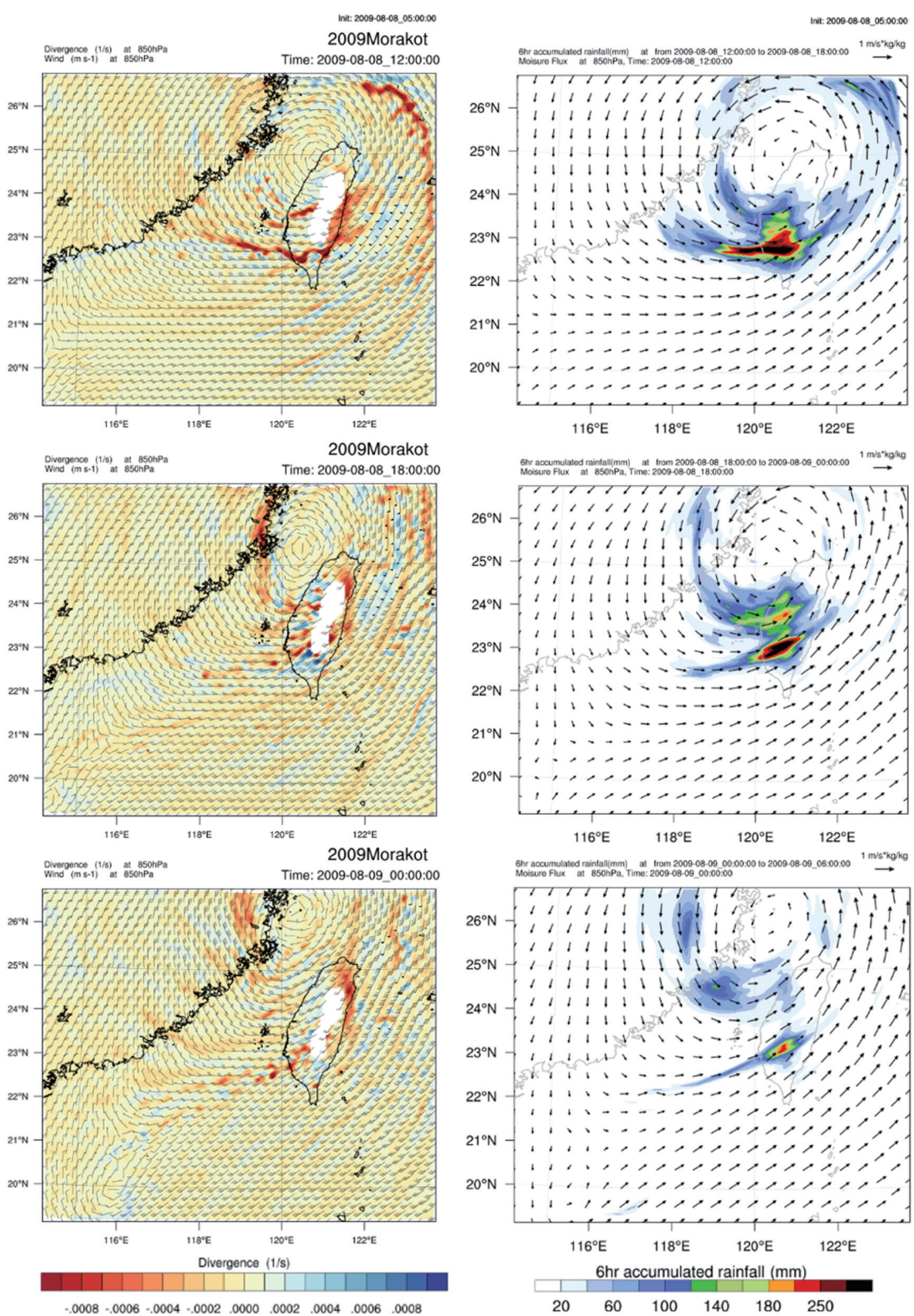

Fig. 10. The control run results from the ARW model for Typhoon Morakot with wind field $\left(\mathrm{m} \mathrm{s}^{-1}\right)$ and the divergence $\left(1 \mathrm{~s}^{-1}\right)$ at $850 \mathrm{hPa}($ left panels) and the corresponded 6-hr accumulated rainfall (mm) and the moisture flux (right panels) from 12:00 to 24:00 UTC on 8 August 2009. The unit of moisture flux is $g \cdot \mathrm{m} / \mathrm{kg} \cdot \mathrm{s}$ after scaled by the constant $g$.

agreement with the wind speed can be found in Fig. 11a. The important role of the SW Asian monsoon circulation in supplying water vapor and then supporting the regional rainfall has been pointed out (Simmonds et al. 1999). The SW monsoon transports water vapor content into the region around southern Taiwan, thereby increasing the regional precipitation. The total precipitation is not merely sensitive to the SW wind speed over southern Taiwan Strait, but also correlated with the transported moisture flux from the ocean.

Accordingly, the SW monsoon moisture flux is analyzed in this study. The moisture flux $(Q)$ at $850 \mathrm{hPa}$ pressure level takes the form shown below.
$Q_{850 \mathrm{hPa}}=\frac{1}{g} q_{850 \mathrm{hPa}} V_{850 \mathrm{hPa}}$

Where $V$ is the horizontal wind vector $\left(\mathrm{m} \mathrm{s}^{-1}\right), q$ is the specific humidity, approximately equivalent to the mixing ratio $\left(\mathrm{g} \mathrm{kg}^{-1}\right)$, and $g$ is the acceleration due to gravity. The panels in Fig. 10 in the right column show the moisture flux at $850 \mathrm{hPa}$ supplying plenty of water content to southern Taiwan. After taking the water vapor into account, the moisture flux effect on the 6-hr accumulated rainfall in southern Taiwan is apparent, as illustrated in Fig. 11b for the case of Typhoon Morakot. The more water content transported 
to southern Taiwan, the greater the amount of precipitation constituted in that area. However, the moisture flux correlation with accumulated rainfall is not as important as the wind speed counterpart. In reviewing Fig. 10, the additional water content is continuously supplied to southern Taiwan in this case. The possible reason could be the constraint of sufficient water content supplied in this case. In other words, the moisture flux effect on the rainfall intensity will be significant before the water content is saturated.

In Fig. 11c, the convergence at $850 \mathrm{hPa}$ and 6-hr accumulated rainfall also has a linear relationship. The results imply that smaller divergence causes greater 6-hr accumulated rainfall amount. This will cause approximately $2 \times 10^{4} \mathrm{~mm}$ per 6 hours rainfall in Area E when $10 \times 10^{-6}$ convergence increases at the $850 \mathrm{hPa}$ level around Area D. The overall SW monsoon variable effects on the accumulated rainfall amount are summarized as regression functions in Table 5 . The SW monsoon wind speed has the highest relationship with precipitation $(\mathrm{R}$-square $=0.96)$ in southern Taiwan.

\section{CONCLUSION}

The statistical results from ECMWF reanalysis dataset show a linear relationship between monsoon and rainfall intensity environmental variables. Nevertheless, the unsurprising finding is that the water vapor content and the wind field convergence both influence rainfall intensity. Thus, extending these complications further and taking advantage of model simulations, this study introduced the WRF model sensitivity experiment with virtual wind field to analyze the problem.

Using 3D-VAR data assimilating virtual wind field can effectively modify the monsoon strength in SCS for further analysis. The heavy rainfall event in southern Taiwan caused from Typhoon Morakot (2009) and the SW monsoon is studied. From the sensitivity experiment, the result demonstrates that the typhoon wind speed increases when the SW monsoon strengthens, and vice versa. The environmental variables analysis shows that the rainfall in Taiwan during the Typhoon Morakot period is greatly associated with the monsoon convergence and wind speed over the southern Taiwan Strait. The impact of moisture flux on the rainfall amount is still evident when sufficient water content was supplied in the case study. Consequently, the SW monsoon variable (i.e., wind speed, convergence, and moisture flux) effects on the accumulated rainfall were quantized based on the Typhoon Morakot (2009) case study. The virtual wind was assimilated in the WRF model in this study but the atmospheric temperature and moisture soundings were not included. With the recent atmospheric profile retrieval algorithm enhancement, e.g., Liu et al. $(2014,2016)$, the detailed SW monsoon circulation and flow pattern description is strengthened. These factors may lead to more realistic case studies to discover more solid SW monsoon effects. The I-TRaP can be expected to improve with the quantitative relationship between rainfall intensity and environmental variables.
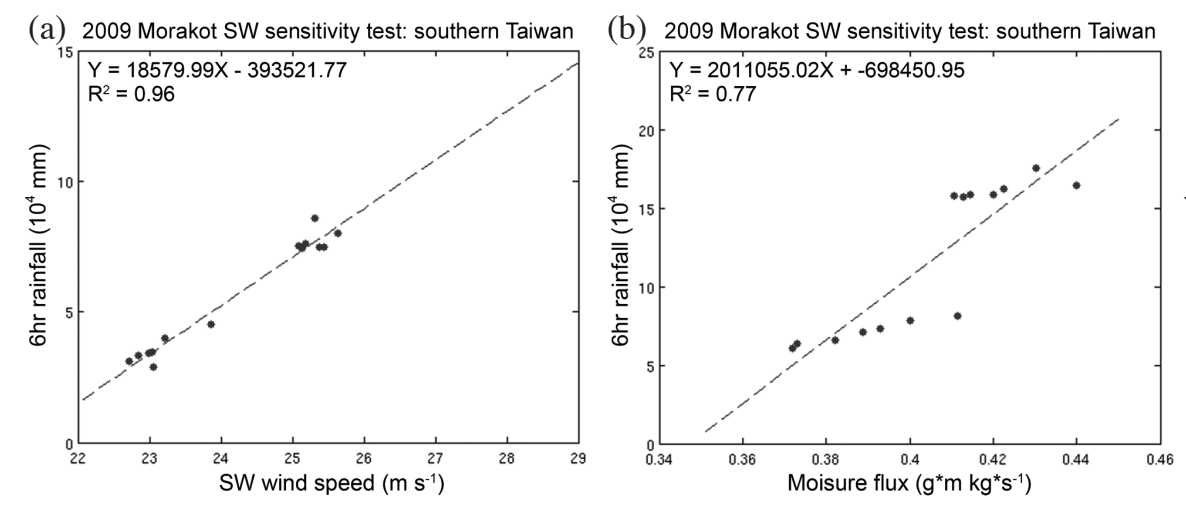

(c) 2009 Morakot SW sensitivity test: southern Taiwan

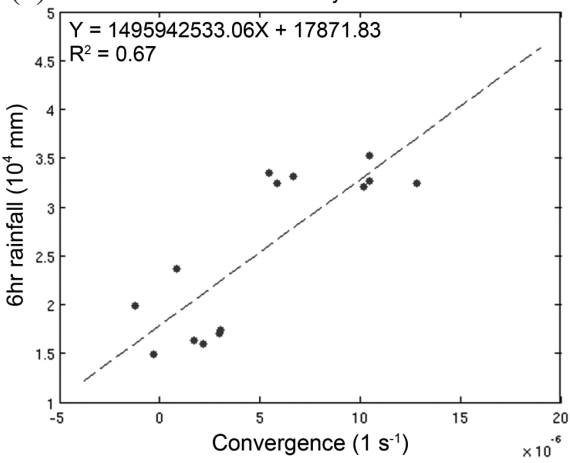

Fig. 11. Scatter plots of 6-hr accumulated rainfall (Area E) with (a) SW wind speed, (b) moisture flux, and (c) convergence at $850 \mathrm{hPa}$ in Area D over southern Taiwan Strait for all sensitivity experiments.

Table 5. The linear regression results between the 6-hr accumulated rainfall amount (Y) and wind speed at, moisture flux and convergence at $850 \mathrm{hPa}$. (X) in regression function represents the total 6-hr accumulated rainfall summed from all grid data in southern Taiwan (A).

\begin{tabular}{ccc}
\hline SW monsoon variable at $850 \mathbf{~} P a$ & Regression Function & R-square \\
\hline Wind Speed $\left(\mathrm{m} \mathrm{s}^{-1}\right)$ & $\mathrm{Y}=1.8 \times 10^{8} \mathrm{X}-3.9 \times 10^{5}$ & 0.96 \\
Moisture Flux $(\mathrm{g} \cdot \mathrm{m} / \mathrm{kg} \cdot \mathrm{s})$ & $\mathrm{Y}=2.0 \times 10^{10} \mathrm{X}-7.0 \times 10^{5}$ & 0.77 \\
Convergence $\left(1 \mathrm{~s}^{-1}\right)$ & $\mathrm{Y}=1.5 \times 10^{13} \mathrm{X}+1.7 \times 10^{4}$ & 0.67 \\
\hline
\end{tabular}


Acknowledgements We are grateful to the Taiwan Ministry of Science and Technology (MOST) for its financial support through Grant MOST 104-2625-M-008-002 and MOST 103-2625-M-008-005 for this study.

\section{REFERENCES}

Chen, G. T. J., C. C. Wang, and D. T. W. Lin, 2005: Characteristics of low-level jets over northern Taiwan in Mei-Yu season and their relationship to heavy rain events. Mon. Weather Rev., 133, 20-43, doi: 10.1175/ MWR-2813.1. [Link]

Cheung, K. K. W., L. R. Huang, and C. S. Lee, 2008: Characteristics of rainfall during tropical cyclone periods in Taiwan. Nat. Hazards Earth Syst. Sci., 8, 1463-1474, doi: 10.5194/nhess-8-1463-2008. [Link]

Chouinard, C., C. Charette, J. Hallé, P. Gauthier, J. Morneau, and R. Sarrazin, 2001: The Canadian 3D-Var analysis scheme on model vertical coordinate. $14^{\text {th }}$ AMS conference on numerical weather prediction, Fort Lauderdale, 30 July-2 August 2001, 14-18.

Dee, D. P, S. M. Uppala, A. J. Simmons, P. Berrisford, P. Poli, S. Kobayashi, U. Andrae, M. A. Balmaseda, G. Balsamo, P. Bauer, P. Bechtold, A. C. M. Beljaars, L. van de Berg, J. Bidlot, N. Bormann, C. Delsol, R. Dragani, M. Fuentes, A. J. Geer, L. Haimberger, S. B. Healy, H. Hersbach, E. V. Hólm, L. Isaksen, P. Kållberg, M. Köhler, M. Matricardi, A. P. McNally, B. M. MongeSanz, J. J. Morcrette, B. K. Park, C. Peubey, P. de Rosnay, C. Tavolato, J. N. Thépaut, and F. Vitart, 2011: The ERA-Interim reanalysis: Configuration and performance of the data assimilation system. Q.J.R. Meteorol. Soc., 137, 553-597, doi: 10.1002/qj.828. [Link]

Dudhia, J., 1989: Numerical study of convection observed during the winter monsoon experiment using a mesoscale two-dimensional model. J. Atmos. Sci., 46, 3077-3107, doi: 10.1175/1520-0469(1989)046<3077: NSOCOD $>2.0 . \mathrm{CO} ; 2$. [Link]

Gauthier,P., C. Charette,L. Fillion, P. Koclas, and S.Laroche, 1999: Implementation of a 3D variational data assimilation system at the Canadian Meteorological Centre. Part I: The global analysis. Atmos.-Ocean, 37, 103-156, doi: 10.1080/07055900.1999.9649623. [Link]

Hong, S. Y., J. Dudhia, and S. H. Chen, 2004: A revised approach to ice microphysical processes for the bulk parameterization of clouds and precipitation. Mon. Weather Rev., 132, 103-120, doi: 10.1175/1520-0493(2004)132<0103:ARATIM>2.0.CO;2. [Link]

Hong, S. Y., Y. Noh, and J. Dudhia, 2006: A new vertical diffusion package with an explicit treatment of entrainment processes. Mon. Weather Rev., 134, 2318-2341, doi: 10.1175/MWR3199.1. [Link]

Kain, J. S., 2004: The Kain-Fritsch convective parameterization: An update. J. Appl. Meteorol. Climatol., 43,
170-181, doi: 10.1175/1520-0450(2004)043<0170:TK CPAU>2.0.CO;2. [Link]

Kidder, S. Q., J. A. Knaff, S. J. Kusselson, M. Turk, R. R. Ferraro, and R. J. Kuligowski, 2005: The tropical rainfall potential (TRaP) technique. Part I: Description and Examples. Weather Forecast., 20, 456-464, doi: 10.1175/WAF860.1. [Link]

Liu, C. Y., G. R. Liu, T. H. Lin, C. C. Liu, H. Ren, and C. C. Young, 2014: Using surface stations to improve sounding retrievals from hyperspectral infrared instruments. IEEE Trans. Geosci. Rem. Sens., 52, 6957-6963, doi:10.1109/TGRS.2014.2305992. [Link]

Liu, C. Y., J. Li, S. P. Ho, G. R. Liu, T. H. Lin, and C. C. Young, 2016: Retrieval of atmospheric thermodynamic state from synergistic use of radio occultation and hyperspectral infrared radiances observations. IEEE J-STARS, 9, 744-756, doi: 10.1109/ JSTARS.2015.2444274. [Link]

Liu, G. R., T. H. Kuo, W. J. Chen, and T. H. Lin, 2012: Prediction of Tropical Cyclone Rainfall Potential in Taiwan Mountainous Areas. In: Wong, T. (Ed.), Rainfall Forecasting, Hydrological Science and Engineering Series, Nova Science Publishers, New York, USA, 283 pp.

Mlawer, E. J., S. J. Taubman, P. D. Brown, M. J. Iacono, and S. A. Clough, 1997: Radiative transfer for inhomogeneous atmosphere: RRTM, a validated correlated-k model for the longwave. J. Geophys. Res., 102, 1666316682, doi: 10.1029/97JD00237. [Link]

National Centers for Environmental Prediction/National Weather Service/NOAA/U.S. Department of Commerce, 2000: NCEP FNL Operational Model Global Tropospheric Analyses, continuing from July 1999. Research Data Archive at the National Center for Atmospheric Research, Computational and Information Systems Laboratory, Boulder, CO, doi: 10.5065/ D6M043C6. [Link]

Simmonds, I., D. Bi, and P. Hope, 1999: Atmospheric water vapor flux and its association with rainfall over China in summer. J. Climate, 12,1353-1367, doi: 10.1175/15 20-0442(1999)012<1353:AWVFAI >2 .0.CO;2. [Link]

Skamarock, W. C., J. B. Klemp, J. Dudhia, D. O. Gill, D. M. Barker, M. G. Duda, X. Y. Huang, W. Wang, and J. G. Powers, 2008: A Description of the Advanced Research WRF Version 3. NCAR Technical Note NCAR/TN475+STR, 113 pp, doi: 10.5065/D68S4MVH. [Link]

Wu, C. C., 2013: Typhoon Morakot: Key findings from the journal $T A O$ for improving prediction of extreme rains at landfall. Bull. Am. Meteorol. Soc., 94, 155-160, doi: 10.1175/BAMS-D-11-00155.1. [Link]

Wu, C. C., K. K. W. Cheung, and Y. Y. Lo, 2009: Numerical study of the rainfall event due to the interaction of Typhoon Babs (1998) and the Northeasterly Monsoon. Mon. Weather Rev., 137, 2049-2064, doi: 10.1175/2009MWR2757.1. [Link] 